\title{
PENERAPAN PEMOTONGAN, PENYETORAN, DAN PELAPORAN PPH FINAL ATAS JASA KONSTRUKSI E-SPT MASA 2017
}

\author{
Daniela Anauskah ${ }^{1)}$ \\ Politeknik LP3I Medan ${ }^{1)}$ \\ Nurlela Hafizah ${ }^{2}$ \\ Pasca Sarjana Universitas Sumatera Utara ${ }^{2)}$
}

*Corresponding author: E-mail: ellaannauskah@gmail.com, nurlela14juni@gmail.com

\begin{abstract}
Abstrak
Penelitian ini bertujuan untuk membantu pihak perusahaan dalam menerapkan Pemotongan, Penyetoran, dan Pelaporan PPh Pasal 4 ayat (2) atas jasa konstruksi oleh WIKA-HUTAMA JO Belawan Fase 2 e-SPT Masa 2017. Periode penelitian ini dimulai dari masa Juli sampai dengan September. Dalam penelitian ini peneliti menggunakan jenis data primer dan data sekunder, sumber data internal, jenis penelitian action research, teknik pengumpulan data wawancara, dokumentasi dan penelitian kepustakaan, serta metode analisis data deskriptif dengan pendekatan kualitatif. Berdasarkan hasil penelitian, Penerapan Pemotongan, Penyetoran, dan Pelaporan PPh Pasal 4 ayat (2) atas Jasa Konstruksi oleh WIKA-HUTAMA JO Belawan Fase 2 eSPT Masa 2017 sudah sesuai dengan ketentuan perpajakan Pajak Penghasilan UU No. 36 Tahun 2008. WIKA-HUTAMA JO mengenakan tarif pajak yang sesuai dengan ketentuan tarif pajak yang berlaku. Kemudian WIKA-HUTAMA JO membuat daftar bukti pemotongan dan mengisi dengan benar dan lengkap bukti pemotongan PPh Pasal 4 Ayat (2) atas Jasa Konstruksi sesuai dengan bentuk dan isian yang telah ditetapkan oleh Dirjen Pajak. Penyetoran PPh pasal 4 Ayat (2) atas Jasa Konstruksi dilakukan sebelum batas akhir penyetoran PPh ke kas negara. Pelaporan PPh pasal 4 Ayat (2) atas Jasa Konstruksi juga dilakukan sebelum batas akhir pelaporan PPh pasal 4 Ayat (2) ke Kantor Pelayanan Pajak.
\end{abstract}

Kata Kunci : e-SPT Masa, PPh Pasal 4 Ayat (2), Jasa Konstruksi

\begin{abstract}
This study aims to assist the company in applying Cutting, Depositing, and Reporting Income Tax Article 4 paragraph (2) for construction services by WIKA-HUTAMA JO Belawan Phase 2 e-SPT Period 2017. The period of this study starts from July to September. In this research the researcher use primary data type and secondary data, internal data source, action research type, interview data collecting technique, documentation and library research, and descriptive data analysis method with qualitative approach. Based on the results of the study, Implementation of Cutting, Depositing, and Reporting Income Tax Article 4 paragraph (2) on Construction Services by WIKAHUTAMA JO Belawan Phase 2 e-SPT 2017 is in accordance with the provisions of taxation Income
\end{abstract}


Tax Law. 36 Year 2008. WIKA-HUTAMA JO impose tax rate in accordance with the provisions of applicable tax rates. Then WIKA-HUTAMA JO creates a list of proof of deduction and fills correctly and complete evidence of withholding of Income Tax Article 4 Paragraph (2) of Construction Services in accordance with the forms and fields specified by the Director General of Taxes. Deposit of Income Tax Article 4 Paragraph (2) of the Construction Service shall be made before the deadline of the withholding of income tax to the state treasury. Reporting of Income Tax Article 4 Paragraph (2) for Construction Services shall also be made before the deadline for reporting the Income Tax Article 4 Paragraph (2) to the Tax Office.

Keywords: e-SPT Period, Income Tax Article 4 Paragraph (2), Construction Services 


\section{PENDAHULUAN}

Penerimaan pajak penghasilan $(\mathrm{PPh})$ merupakan salah satu penerimaan terbesar dari sektor pajak.Salah satu PPh yang memiliki kontribusi terbesar dari sektor pajak adalah PPh pasal 4 ayat (2). Dimana $\mathrm{PPh}$ pasal 4 ayat (2) telah menyumbang pendapatan sebesar Rp 120.113.943.297.708 pada tahun 2015 dan Rp 118.247.987.704.062 pada tahun 2016, ini menunjukkan bahwa penerimaan $\mathrm{PPh}$ pasal 4 ayat (2) menurun sebesar $1,55 \%$ dari tahun sebelumnya. Dikarenakan hal tersebut, maka pemerintah mulai melakukan sosialisasi kepada masyarakat tentang pentingnya pajak bagi negara dengan memberikan kemudahan dalam pemotongan, penyetoran, dan pelaporan dalam bentuk aplikasi e-SPT masa $\mathrm{PPh}$ pasal 4 ayat (2).

WIKA-HUTAMA JO berkewajiban memotong beberapa Pajak Penghasilan atas jasa yang WIKA-Hutama JO terima, salah satunya PPh Pasal 4 ayat (2). Berdasarkan prareset yang dilakukan peneliti telah menemukan beberapa kendala dalam pengisian e-SPT Pajak Penghasilan yang disebabkan karena kurang siap dari sumber daya manusia.Hal ini terlihat dari adanya empat kali pembetulan SPT PPh Pasal 4 ayat (2) yang mengakibatkan keterlambatan pembayaran dan pelaporan. Beranjak dari uraian diatas maka peneliti tertarik untuk membuat suatu karya ilmiah yang berjudul "Penerapan Pemotongan, Penyetoran, dan Pelaporan PPh Pasal 4 Ayat (2) atas Jasa Konstruksi oleh WIKA-HUTAMA JO Belawan Fase 2 e-SPT Masa 2017 ".

Adapun tujuan dalam penelitian ini adalah untuk membantu pihak perusahaan dalam menerapkan Pemotongan, Penyetoran, dan Pelaporan PPh Pasal 4 ayat
(2) atas jasa konstruksi oleh WIKAHUTAMA JO Belawan Fase 2 e-SPT Masa 2017.

\section{Pengertian Pajak}

Menurut UU KUP Nomor 16 Tahun 2009 Pasal 1 Ayat (1)Pajak adalah kontribusi wajib pajak kepada negara yang terutang oleh orang pribadi atau badan yang bersifat memaksa berdasarkan UU dengan tidak mendapatkan imbalan secara langsung dan digunakan untuk keperluan negara bagi sebesar-besarnya kemakmuran rakyat.

\section{PPh Pasal 4 ayat (2)}

Berdasarkan UU Perpajakan No. 36 tahun 2008, pajak penghasilan yang bersifat final terdiri atas :

1. Penghasilan berupa bunga deposito dan tabungan lainnya, bunga obligasi dan surat utang negara, dan bunga simpanan yang dibayarkan oleh koperasi kepada anggota koperasi orang pribadi;

2. Penghasilan berupa hadiah undian;

3. Penghasilan dari transaksi saham dan sekuritas lainnya, transaksi derivatif yang diperdagangkan di bursa, dan transaksi penjualan saham atau pengalihan penyertaan modal pada perusahaan pasangannya yang diterima oleh perusahaan modal ventura;

4. Penghasilan dari transaksi pengalihan harta berupa tanah dan/atau bangunan;

5. Usaha jasa konstruksi, usaha real estate, dan persewaan tanah dan/atau bangunan; dan

6. Penghasilan tertentu lainnya, yang diatur dengan atau berdasarkan Peraturan Pemerintah. 


\section{Ketentuan PPh pasal 4 ayat (2) atas Usaha Jasa Konstruksi}

Usaha jasa konstruksi memiliki aspek-aspek perpajakan dimana salah satunya adalah pengenaan pajak penghasilan. Ketentuan perpajakan mengenai jasa konstruksi mulai tahun 2001 mengikuti ketentuan yang diatur dalam PP No. 140 tahun 2000, PMK No. 153/PMK.03/2009 tentang perubahan atas peraturan menteri keuangan nomor 187/PMK.03/2008, serta Peraturan DJP No. Per-70/PJ/2007 tentang Jenis Jasa Lain dan Perkiraan Penghasilan Neto sebagaimana dimaksud dalam pasal 23 ayat (1) huruf $\mathrm{c}$ dan SE DJP No.SE-13PJ.42/2002 tentang pelaksanaan Perlakuan Pajak Penghasilan atas Penghasilan dari Usaha Jasa Konstruksi.Dalam keempat peraturan tersebut, pengenaan pajak penghasilan atas jasa konstruksi dibedakan menjadi bersifat Final dan Tidak Final yang tergantung dari kualifikasi wajib pajak sebagai pengusaha di bidang jasa konstruksi kecil atau besar.

Pengertian kualifikasi menurut Pasal 1 Ayat (3) PP No. 28 Tahun 2000 "Kualifikasi adalah bagian kegiatan registrasi untuk menetapkan penggolongan usaha di bidang jasa konstruksi menurut tingkat ataukedalaman kompetensi dan kemampuan usaha, atau penggolongan profesi keterampilan dan keahlian kerja orang perseorangan di bidang jasa konstruksi menurut tingkat atau kedalaman kompetensi dan kemampuan profesi dan keahlian."

Sedangkan, klasifikasi usaha jasa konstruksi menurut PP No. 28 Tahun 2000, terdiri dari:

a. Klasifikasi usaha bersifat umum yang diberlakukan kepada badan usaha yang mempunyai kemampuan untuk melaksanakan satu atau lebih bidang pekerjaan;

b. Klasifikasi usaha bersifat spesialis yang diberlakukan kepada usaha orang perseorangan dan atau badan usaha yang mempunyai kemampuan hanya melaksanakan satu sub bidang atau satu bagian sub bidang;

c. Klasifikasi usaha orang perseorangan yang berketrampilan kerja tertentu diberlakukan kepada usaha orang perseorangan yang mempunyai kemampuan hanya melaksanakan suatu keterampilan kerja tertentu.

\section{Tarif}

Wajib Pajak dalam negeri dan Bentuk Usaha Tetap (BUT) yang menerima penghasilan dari jasa konstruksi dikenakan Pajak Penghasilan dengan tarif sebagai berikut:

Tabel 2.1 Tarif Jasa Konstruksi berdasarkan jenis kegiatan dan kualifikasi

\begin{tabular}{|c|c|l|c|}
\hline No. & \multicolumn{1}{|c|}{ Jenis Kegiatan } & \multicolumn{1}{|c|}{ Kualifikasi } & Tarif \\
\hline 1. & Pelaksanaan Konstruksi & Kualifikasi kecil & $2 \%$ \\
\hline 2. & Pelaksanaan Konstruksi & Kualifikasi & $3 \%$ \\
\hline
\end{tabular}




\begin{tabular}{|c|l|l|c|}
\hline & & menengah \& besar & \\
\hline 3. & Pelaksanaan Konstruksi & $\begin{array}{l}\text { Tidak mempunyai } \\
\text { kualifikasi }\end{array}$ & $4 \%$ \\
\hline 4. & $\begin{array}{l}\text { Perencanaan dan } \\
\text { Pengawasan Konstruksi }\end{array}$ & $\begin{array}{l}\text { Mempunyai } \\
\text { kualifikasi }\end{array}$ & $4 \%$ \\
\hline 5. & $\begin{array}{l}\text { Perencanaan dan } \\
\text { Pengawasan Konstruksi }\end{array}$ & $\begin{array}{l}\text { Tidak mempunyai } \\
\text { kualifikasi }\end{array}$ & $6 \%$ \\
\hline
\end{tabular}

Sumber: Kementrian Keuangan RI DJP

\section{Dasar Pengenaan Pajak}

PPh Final jasa konstruksi dihitung dengan cara mengalikan tarif di atas dengan Dasar Pengenaan Pajak (DPP). Menurut Pasal 4 ayat (2) PMK Nomor 153/PMK.03/2009, DPP yang digunakan untuk menghitung PPh Final jasa konstruksi adalah:

a. Jumlah Pembayaran, apabila PPh Final jasa konstruksi dikenakan melalui pemotongan $\mathrm{PPh}$ oleh pengguna jasa (pemilik proyek atau owner);

b. Jumlah Penerimaan Pembayaran, apabila PPh Final jasa konstruksi dikenakan melalui penyetoran sendiri oleh kontraktor yang bersangkutan.

\section{Pengertian SPT}

Surat Pemberitahuan adalah surat yang oleh wajib pajak digunakan untuk melaporkan perhitungan dan/atau pembayaran pajak, objek pajak dan /atau bukan objek pajak, dan/atau harta dan kewajiban sesuai dengan ketentuan peraturan perundang-undangan perpajakan.

\section{Bentuk SPT}

Bentuk SPT dibagi menjadi dua, yaitu :

1. Formulir kertas (hardcopy)
2. e-SPT

\section{METODE PENELITIAN}

\section{Tempat dan Waktu Penelitian}

Penelitian dilakukan pada WIKAHUTAMA JO yang beralamat di Komplek Cemara Hijau Blok G No. 9, dan waktu penelitian di mulai bulan November 2017 sampai Februari 2018.

\section{Jenis dan Sumber Data}

1. Jenis Data

Jenis data yang digunakan dalam penelitian ini terdiri dari :

a. Data Primer

Data Primer adalah data atau informasi yang belum diolah perusahaan, diperoleh melalui wawancara.

b. Data Sekunder

Data Sekunder adalah data yang sudah tersedia dari perusahaan langsung sehingga siap digunakan, seperti SPT Masa PPh Pasal 4 ayat (2) atas jasa konstruksi dan data-data lain yang sehubungan dengan objek penelitian, yang dihasilkan dari aplikasi e-SPT masa PPh pasal 4 ayat (2). 
2. Sumber Data

Sumber data yang digunakan peneliti adalah Data Internal yaitu data yang diperoleh dari perusahaan dibagian Akuntansi seperti, Daftar Subkon, Pendapatan atas Jasa Konstruksi dan dokumen-dokumen pendukung lainnya terkait dengan pembuatan $\mathrm{PPh}$ pasal 4 ayat (2).

\section{Jenis Penelitian}

Jenis penelitian yang dilaksanakan oleh peneliti dalam melakukan penelitian ini adalah Action Research atau penelitian tindakan. Peneliti mulai melakukan rancangan penelitian tindakan pada bulan September dimana peneliti berpartisipasi secara langsung dalam proses pemotongan, penyetoran dan pelaporan $\mathrm{PPh}$ pasal 4 ayat (2) atas jasa konstruksi oleh WIKAHUTAMA JO e-SPT masa 2017.

\section{Teknik Pengumpulan Data}

Ada dua hal yang mempengaruhi kualitas data hasil penelitian, baik itu penelitian kualitatif maupun kuantitatif.Dua hal itu adalah kualitas instrumen penelitian dan kualitas pengumpulan data. Teknik yang dilakukan penulis dalam pengumpulan data yaitu :

\section{Wawancara}

Wawancara yaitu teknik pengumpulan data dengan mengadakan tanya jawab secara langsung dengan responden, yaitu bagian pajak dan keuangan WIKA-HUTAMA JO menghitung, menyetor dan melaporkan PPh Pasal 4 ayat (2) atas jasa konstruksi.

2. Dokumentasi

Dokumentasi yaitu melalui pencatatan dan pengkopian atas data-data dari WIKA-HUTAMA JO dalam bentuk yang sudah jadi misalnya, struktur organisasi, uraian jabatan yang berkaitan dengan objek penelitian.

3. Penelitian Kepustakaan (Library
Research)

Penelitian Kepustakaan ialah pengumpulan data-data yang dilakukan melalui studi pustaka dengan menggunakan buku-buku dari sumber lainnyayang berkaitan dengan PPh Pasal 4 Ayat (2).

\section{Metode Analisis Data}

Metode analisis data yang digunakan peneliti berupa :

1. Metode Deskriptif

Metode deskriptif adalah suatu metode yang dilakukan dengan mengumpulkan, mengklasifikasikan, menganalisis serta menginterprestasikan data sehingga memberikan keterangan yang lengkap bagi pemecahan permasalahan yang terjadi.

\section{Metode Kualitatif}

Menurut Strauss dan Corbin (V. Wiratna Sujarweni 2015 : 11), yang dimaksud dengan penelitian kualitatif adalah jenis penelitian yang menghasilkan penemuan penumuan yang tidak dicapai (diperoleh) dengan menggunakan prosedur-prosedur statistic atau cara-cara lain kuantifikasi (pengukuran).

Berdasarkan pengertian diatas, maka peneliti tidak menggunakan analisis statistik. Teknik tersebut terdiri dari :

a. Menganalisa perhitungan penghasilan untuk menghasilkan besarnya PPh Pasal 4 ayat (2) atas jasa konstruksi.

b. Menganalisa penyetoran yang dilakukan perusahaan, pengisian SPT Masa PPh Pasal 4 ayat (2) atas jasa konstruksi serta penyetorannya. 
c. Menganalisa pelaporan yang dilakukan perusahaan, penginputan SSE PPh Pasal 4 ayat (2) atas jasa konstruksi serta pelaporannya.

\section{HASIL PENELITIAN}

\section{Hasil Penelitian}

Berdasarkan hasil penelitian, Penerapan Pemotongan, Penyetoran, dan Pelaporan PPh Pasal 4 ayat (2) atas Jasa Konstruksi oleh WIKA-HUTAMA JO Belawan Fase 2 e-SPT Masa 2017 sudah sesuai dengan ketentuan perpajakan Pajak Penghasilan UU No. 36 Tahun 2008. WIKA-HUTAMA JO mengenakan tarif pajak yang sesuai dengan ketentuan tarif pajak yang berlaku. Kemudian WIKAHUTAMA JO membuat daftar bukti pemotongan dan mengisi dengan benar dan lengkap bukti pemotongan PPh Pasal 4 Ayat (2) atas Jasa Konstruksi sesuai dengan bentuk dan isian yang telah ditetapkan oleh Dirjen Pajak. Penyetoran PPh pasal 4 Ayat (2) atas Jasa Konstruksi dilakukan sebelum batas akhir penyetoran $\mathrm{PPh}$ ke kas negara.Pelaporan $\mathrm{PPh}$ pasal 4 Ayat (2) atas Jasa Konstruksi juga dilakukan sebelum batas akhir pelaporan PPh pasal 4 Ayat (2) ke Kantor Pelayanan Pajak.

\section{Pembuatan Database Perusahaan}

Database Perusahaan diperlukan dalam aplikasi e-SPT Masa PPh Pasal 4 ayat (2) sebagai data . Langkah-langkah pembuatan Database Perusahaan adalah sebagai berikut :

1. Copy Database kosong yang ada pada aplikasi e-SPT PPh Pasal 4 ayat (2). Rename Database kosong yang dicopy sebelumnya menjadi nama Perusahaan.

2. Buka Control Panel, lalu pilih Administrative Tools, pilih ODBC Data Sources (32-bit), pilih System DSN, lalu pilih Database yang telah direname sebelumnya, Klik Add, pilih Microsoft Access Driver (*.mdb), Klik Finish.

\section{Deskripsi Data PPh Pasal 4 ayat (2) atas Jasa Konstruksi}

Data-data yang diperlukan dalam penelitian ini adalah data-data yang berkaitan dengan pajak penghasilan terutang perusahaan, yaitu data pembayaran Subkrontraktor beserta bukti potongnya, data penyetoran $\mathrm{PPh}$ pasal 4 ayat (2) atas jasa konstruksi ke kas negara, serta SPT masa PPh Final pasal 4 ayat (2) yang didapat dari WIKA-HUTAMA JO dalam kurun waktu selama tiga bulan (bulan Juli, Agustus, dan September) pada tahun 2017.

Berikut adalah data pembayaran Subkontraktor oleh WIKA-HUTAMA JO dalam masa pajak Juli 2017.

Tabel 4.1Data Pembayaran Subkontraktor

Sumber : WIKA-HUTAMA JO

\section{Penerapan PPh Pasal 4 ayat (2) atas Jasa Konstruksi}

Langkah-langkah yang akan ditempuh dalam menjawab rumusan masalah adalah sebagai berikut:

1. Perhitungan $\mathrm{PPh}$ Terutang dan Pemotongan PPh Pasal 4 Ayat (2) atas Jasa Konstruksi

$\mathrm{PPh}$ terutang diperoleh dari perkalian tarif $\mathrm{PPh}$ Final sesuai dengan kualifikasi usaha berdasarkan SIUJK yang dikeluarkan oleh LPJK. Adapun totalpembayaran WIKA-HUTAMA JO ke subkontraktor adalah sebesar Rp. 1.624.656.904 dan PPh pasal 4 ayat (2) yang harus dibayarkan ke kas negara adalah sebesar Rp. 52.197.534 dengan perincian sebagai berikut 
Tabel

4.2PPh

Terutang

\begin{tabular}{|c|c|c|c|}
\hline No & Nama Subkontraktor & $\begin{array}{c}\text { Tanggal } \\
\text { Pembayaran }\end{array}$ & Total Pembayaran \\
\hline 1. & $\begin{array}{c}\text { PT Teknindo } \\
\text { Geosistem Unggul }\end{array}$ & $21 / 07 / 2017$ & Rp 1.278.874.222 \\
\hline 2. & $\begin{array}{c}\text { PT Darma Bakti } \\
\text { Selaras (Daphas) }\end{array}$ & $31 / 07 / 2017$ & $\mathrm{Rp} \mathrm{345.782.682}$ \\
\hline
\end{tabular}

Juli

\begin{tabular}{|c|c|c|l|c|}
\hline No & Nama Subkontraktor & $\begin{array}{c}\text { Tanggal } \\
\text { Pembayaran }\end{array}$ & Total Pembayaran & PPh Terutang \\
\hline 1. & $\begin{array}{c}\text { PT Teknindo } \\
\text { Geosistem Unggul }\end{array}$ & $21 / 07 / 2017$ & Rp 1.278.874.222 & Rp 38.366.227 \\
\hline 2. & $\begin{array}{c}\text { PT Darma Bakti } \\
\text { Selaras (Daphas) }\end{array}$ & $31 / 07 / 2017$ & $\mathrm{Rp} 345.782 .682$ & $\mathrm{Rp} 13.831 .307$ \\
\hline
\end{tabular}

Sumber: WIKA-HUTAMA JO

Pemotongan PPh Pasal 4 ayat (2) atas jasa konstruksi dilakukan pada saat pembayaran dilakukan atau saat disediakan ataupun ketika pembayaran telah jatuh tempo.

2. Penginputan Transaksi ke e-SPT

Semua transaksi pemotongan pajak penghasilan diinput ke aplikasi eSPT PPh pasal 4 ayat (2). Adapun cara penginputan transaksi pemotongan pajak ke aplikasi eSPT adalah sebagai berikut :

a. Terlebih dahulu login di aplikasi eSPT PPh Pasal 4 ayat (2) dengan cara ketik administrator pada kolom USER NAME dan 123 pada kolom PASSWORD

b. Klik Tab Program, lalu klik buat SPT baru. Pilih Masa Pajak Juli, Tahun Pajak 2017, lalu klik Buat.

c. Pilih Tab SPT PPh, lalu pilih Daftar Bukti Pemotongan/Pemungutan PPh Final Pasal 4 ayat (2). Klik Baru, Lalu Klik Penghasilan Atas Usaha
Jasa Konstruksi. Isi data ke Bukti Pemotongan, lalu klik Simpan.

3. Pencetakan Bukti Potong

Setelah selesai diinput, Bukti Potong dicetak, ditandatangani, dan diberi stempel perusahaan, lalu kemudian 1 lembar bukti potong diberikan ke subkontraktor sebagai bukti bahwa penghasilan mereka telah dipotong PPh Pasal 4 ayat (2) atas jasa konstruksi oleh WIKA-HUTAMA JO. Ada 3 metode pencetakan Bukti Potong PPh Pasal 4 ayat (2), yaitu :

a. Langsung dari menu Pengisian Bukti Potong ketika melakukan penginputan (Klik Cetak ketika selesai menginput).

b. Dari Daftar Bukti Pemotongan/ Pemungutan PPh Pasal 4 ayat (2). Pilih Bukti Potong yang akan dicetak, klik Bukti Potong/Pungut PPh Pasal 4 ayat (2) Pihak Lain yang Dipotong, lalu klik Cetak. 
c. Dari menu SPT Tools di bagian depan aplikasi eSPT PPh Pasal 4 ayat (2). Klik SPT Tools, lalu klik menu cetakan. Isikan Masa dan Tahun Pajak yang ingin dicetak bukti potongnya pada Masa Pajak/Tahun Pajak. Pilih Bukti Potong yang ingin dicetak, lalu klik Cetak.

4. Pengisian Surat Setoran Elektronik (SSE)

Prosedur pembuatan SSE adalah sebagai berikut:

a. Buka djponline.pajak.go.iddi web browser, lalu isikan NPWP, password, dan kode keamanan, lalu Klik Login.

b. Pilih e-Billing System. Pilih Isi SSE. Isi Jenis Pajak, Jenis Setoran, Masa Pajak, Tahun Pajak, dan Jumlah Setor, lalu klik Simpan.

c. Muncul PopUp "Apakah data yang anda isikan sudah benar?", lalu klik Ya.

d. Muncul PopUp "Rekam SSP berhasil dengan Nomor Transaksi : A18229103276. Silahkan klik tombol 'Ubah SSP' untuk mengubah atau klik tombol 'Kode Billing' untuk melanjutkan." Lalu Klik OK.

e. Klik Kode Billing, muncul PopUp "Pembuatan ID Billing Sukses." Lalu Klik OK.

f. Setelah Kode Billing keluar, klik cetak kode billing. SSE siap untuk dicetak.

5. Penyetoran $\mathrm{PPh}$ Terutang ke Kas Negara

SSE yang telah dicetak tadi berisi Kode Billing, yang merupakan dasar untuk melakukan penyetoran $\mathrm{PPh}$ terutang ke kas negara. Penyetoran dapat dilakukan melalui ATM, Internet Banking, Mobile Banking, pembayaran langsung ke Teller Bank, dan melalui kantor pos. Berdasarkan penelitian yang dilakukan, WIKA-HUTAMA JO sendiri melakukan penyetoran pajak melalui teller Bank Mandiri. Penyetoran PPh Pasal 4 Ayat (2) sendiri dilakukan WIKA-HUTAMA JO pada Agustus
2017. Setelah dilakukan pembayaran maka didapatlah Bukti Pembayaran yang divalidasi bank yang di dalamnya terdapat Nomor Transaksi Penerimaan Negara (NTPN) sebagai bukti bahwa $\mathrm{PPh}$ terutang telah dibayarkan ke Kas Negara.

6. Pelaporan

Setelah memperoleh Bukti Pembayaran, maka langkah selanjutnya adalah menginput ke e-SPT bahwa kita telah melakukan pembayaran pajak. Langkah-langkah yang harus dilakukan adalah sebagai berikut:

a. Klik SPT PPh, Klik Daftar Surat Setoran Pajak (SSP)/Bukti Pemindahbukuan (PBK), lalu klik Daftar Surat Setoran Pajak.

b. Klik Baru, Lalu isi uraian pembayaran sesuai dengan Bukti Pembayaran yang diterima, lalu klik simpan.

Setelah dilakukan penginputan bukti pembayaran, maka yang harus dilakukan adalah pencetakan SPT PPh Pasal 4 ayat (2) Masa Juli tahun 2017 untuk kemudian dilaporkan ke KPP. Adapun langkah-langkah pembuatan SPT melalui eSPT PPh pasal 4 ayat (2) adalah sebagai berikut :

a. Klik SPT PPh, lalu klik Surat Pemberitahuan (SPT) Masa PPh Pasal 4 ayat (2).

b. Pilih Halaman 2, isi tanggal, lalu klik Simpan, kemudian klik Cetak.

Untuk melapor SPT ke KPP, kita harus membawa SPT induk, Bukti Pembayaran Pajak, beserta data SPT dalam format CSV yang diisikan ke dalam CD/Flashdisk. Adapun langkahlangkah pembuatan data SPT dan penyimpanannya adalah sebagai berikut

a. Pilih SPT Tools, lalu pilih Lapor Data SPT Ke KPP. 
b. Pilih Masa Pajak dan Tahun Pajak, kemudian pilih data yang akan disimpan ke CD/Flashdisk, setelah itu tentukan Lokasi Penyimpanan, kemudian klik Create File.

Setelah semua selesai dilakukan, maka tahapan terakhir adalah Pelaporan SPT PPh Pasal 4 ayat (2) ke Kantor Pelayanan Pajak. Setelah selesai melapor, KPP akan memberikan 1 lembar Bukti Penerimaan Surat (BPS) sebagai bukti bahwa wajib pajak telah melakukan pelaporan SPT dan SPT telah diterima oleh KPP. Berdasarkan penelitian yang dilakukan, diketahui bahwa WIKA-HUTAMA JO sendiri terdaftar di KPP Pratama Medan Timur.Maka pelaporan SPT dilakukan di
KPP Pratama Medan Timur dengan membawa SPT Induk, Bukti Pembayaran Pajak, beserta data SPT dalam format CSV yang diisikan ke CD/Flashdisk. WIKA-HUTAMA JO sendiri melakukan pelaporan SPT PPh Pasal 4 ayat (2) Masa Juli Tahun Pajak 2017 pada Agustus 2017, terlihat pada Bukti Penerimaan Surat (BPS) yang dikeluarkan oleh KPP Pratama Medan Timur.

Berikut merupakan tabel $\mathrm{PPh}$ terutang selama bulan Agustus dan Sebtember beserta dengan daftar bukti potong dan SPT masa halaman 2 dari aplikasi e-SPT masa PPh pasal 4 ayat (2).

Tabel 4.3PPh Terutang Agustus

\begin{tabular}{|c|c|c|c|l|l|}
\hline No & $\begin{array}{c}\text { Nama } \\
\text { Subkontraktor }\end{array}$ & $\begin{array}{c}\text { Tanggal } \\
\text { Pembayaran }\end{array}$ & Total Pembayaran & \multicolumn{2}{|c|}{ PPh Terutang } \\
\hline 1. & $\begin{array}{c}\text { PT Soedharso } \\
\text { Sentra Jasa }\end{array}$ & $09 / 08 / 2017$ & $\mathrm{Rp} 4.467 .351 .000$ & $\mathrm{Rp}$ & 134.020 .530 \\
\hline 2. & $\begin{array}{c}\text { PT Soedharso } \\
\text { Sentra Jasa }\end{array}$ & $09 / 08 / 2017$ & $\mathrm{Rp} 2.095 .149 .000$ & $\mathrm{Rp}$ & 62.854 .470 \\
\hline 3 & $\begin{array}{c}\text { PT Van Oord } \\
\text { Indonesia }\end{array}$ & $29 / 08 / 2017$ & $\mathrm{Rp} \mathrm{50.344.405.000}$ & $\mathrm{Rp}$ & 1.510 .332 .150 \\
\hline 4 & $\begin{array}{c}\text { PT Cakra } \\
\text { Multi Perkasa }\end{array}$ & $30 / 08 / 2017$ & $\mathrm{Rp} 1.175 .576 .040$ & $\mathrm{Rp}$ & 32.267 .281 \\
\hline 5 & $\begin{array}{c}\text { PT Cakra } \\
\text { Multi Perkasa }\end{array}$ & $30 / 08 / 2017$ & $\mathrm{Rp} 1.150 .000 .000$ & $\mathrm{Rp}$ & 34.500 .000 \\
\hline
\end{tabular}

Sumber : WIKA-HUTAMA JO

Tabel 4.4PPh Terutang September

\begin{tabular}{|c|c|c|c|c|c|c|}
\hline No & Nama Subkontraktor & $\begin{array}{c}\text { Tanggal } \\
\text { Pembayaran }\end{array}$ & & al Pembayaran & \multicolumn{2}{|c|}{ PPh Terutang } \\
\hline 1. & $\begin{array}{c}\text { PT Teknindo Geosistem } \\
\text { Unggul }\end{array}$ & $15 / 09 / 2017$ & $\mathrm{Rp}$ & 104.915 .000 & $\mathrm{Rp}$ & 3.147 .450 \\
\hline 2. & $\begin{array}{c}\text { PT Teknindo Geosistem } \\
\text { Unggul }\end{array}$ & $12 / 09 / 2017$ & $\mathrm{Rp}$ & 7.069 .479 .935 & $\mathrm{Rp}$ & 212.084 .399 \\
\hline
\end{tabular}

Sumber : WIKA-HUTAMA JO 
Tata Cara Pemotongan, Penyetoran, dan Pelaporan PPh Pasal 4 ayat (2) atas Jasa Konstruksi

Tata cara pemotongan, penyetoran, dan pelaporan PPh Pasal 4 ayat (2) atas Jasa Konstruksi adalah sebagai berikut :

1. Tata cara pemotongan PPh pasal 4 Ayat (2) atas Jasa Konstruksi berdasarkan Peraturan Menteri Keuangan nomor 153/PMK.03/2009:

a. Pemotongan PPh Pasal 4 Ayat (2) Atas Jasa Konstruksi dilakukan dengan memberikan bukti pemotongan yang telah diisi lengkap.

b. Pemotongan PPh Pasal 4 Ayat (2) Atas Jasa Konstruksi dilakukan pada saat pembayaran dilakukan atau saat disediakan ataupun ketika pembayaran telah jatuh tempo.

c. Lembar ke-1 bukti pemotongan diserahkan kepada wajib pajak rekanan.

2. Tata cara penyetoran PPh pasal 4 Ayat (2) atas Jasa Konstruksi sesuai dengan Peraturan Menteri Keuangan nomor 242/PMK.03/2014:

a. PPh Pasal 4 Ayat (2) Atas Jasa Konstruksi yang tercantum dalam bukti pemotongan selama satu bulan takwim dijumlahkan.

b. Jumlah PPh pasal 4 Ayat 2 Atas Jasa Konstruksi yang telah dipotong selama satu bulan takwin disetor ke Bank persepsi atau Kantor Pos dengan menggunakan SSP paling lambat tanggal 10 bulan takwim berikutnya setelah bulan saat terutangnya pajak oleh bendahara. Apabila tanggal 10 jatuh pada hari libur, maka penyetoran dilakukan pada hari kerja berikutnya.

3. Tata cara pelaporan $\mathrm{PPh}$ Pasal 4 ayat (2) atas Jasa Konstruksi sesuai dengan Peraturan Menteri Keuangan nomor 243/PMK.03/2014 :

a. Bendahara mengisi dengan lengkap dan benar formulir SPT Masa PPh Pasal 4 ayat (2) dan dilampiri dengan bukti setoran ke kas negara serta data SPT dalam bentuk CSV yang telah diisikan ke CD/flashdisk.

b. SPT Masa PPh Pasal 4 ayat (2) lengkap bersama lampirannya harus dilaporkan ke KPP selambat-lambatnya tanggal 20 bulan berikutnya dan disampaikan langsung atau dikirim melalui pos tercatat. Jika tanggal 20 jatuh pada hari libur, maka pelaporan dilakukan pada hari kerja berikutnya.

c. Bendahara menerima kembali satu lembar Bukti Penerimaan Surat (BPS) dari KPP, sebagai bukti telah melapor.

\section{Kendala dalam Penerapan PPh Pasal 4 ayat (2) atas Jasa Konstruksi}

Dalam penerapan pemotongan, penyetoran, dan pelaporan $\mathrm{PPh}$ Pasal 4 Ayat (2) dengan menggunakan aplikasi e-SPT masih ditemukan beberapa kendala, salah satunya adalah kurangnya pemahaman masyarakat dalam menggunakan aplikasi tersebut. Hal tersebut dapat terjadi kerena kurangnya sosialisasi pemerintah tentang bagaimana cara penggunaan aplikasi e-SPT.

Kendala di WKA-HUTAMA JO sendiri terletak dibagian staf perpajakannya yang masih belum paham dan kurang teliti dalam menggunakan aplikasi e-SPT. Dikarenakan hal tersebut, maka sering sekali terjadi pembetulan yang dapat menghabiskan biaya.Kekurangpahaman staf perpajakan di WIKA-HUTAMA JO disebabkan kurangnya pelatihan atau tidak tepatnya pelatihan yang diberikan.

\section{KESIMPULAN DAN SARAN}

\section{Kesimpulan}

Berdasarkan penelitian ini maka dapat ditarik kesimpulan bahwa penerapan pemotongan, penyetoran, dan pelaporan $\mathrm{PPh}$ 
Pasal 4 ayat (2) atas jasa konstruksi yang dilakukan oleh WIKA-HUTAMA JO untuk masa pajak Juli sampai dengan September tahun pajak 2017 sudah sesuai dengan peraturan perpajakan, akan tetapi masih ditemukan kendala dalam pengerjaannya yang meliputi ketidaksiapan sumberdaya manusia.

\section{Saran}

Berdasarkan dari penelitian ini maka peneliti ingin memberikan sedikit saran bahwa ada baiknya pihak kepala seksi dan manajer melakukan evaluasi atau double check terhadap kinerja pegawai terlebih pada pegawai perpajakan yang memiliki resiko lebih besar karena menyangkut ranah hukum, dan pegawai perusahaan sebaiknya dibekali dengan pengetahuan mengenai penerapan pemotongan, penyetoran dan pelaporan secara e-SPT yang benar dan sesuai dengan cara mengikutsertakan staf perpajakan dalam pelatihan. Agar dapat melakukan pemotongan, penyetoran dan pelaporan $\mathrm{PPh}$ pasal 4 ayat (2) atas jasa konstruksi sesuai dengan ketentuan Undang -Undang perpajakan yang berlaku.

\section{DAFTAR PUSTAKA}

H, A. dkk, 2014.Perpajakan (Konsep, Aplikasi, Contoh, dan Studi Kasus). Jakarta,Salemba Empat

S, V. Wiratna (2015).Metodologi PenelitianBisnis \& Ekonomi. Yogyakarta, Pustakabarupress

Peraturan Direktorat Jenderal Pajak No.Per70/PJ/2007.Jenis Jasa Lain Dan Perkiraan Penghasilan Neto. Direktorat Jenderal Pajak Republik Indonesia
Peraturan Menteri Keuangan Nomor 153/PMK.03/2009.Perubahan atas Peraturan Menteri Keuangan Nomor 187/PMK.03/2008. Menteri Keuangan Republik Indonesia

Peraturan Menteri Keuangan Nomor 242/PMK.03/2014.Tata Cara Pembayaran dan Penyetoran Pajak.Menteri Keuangan Republik Indonesia

Peraturan Menteri Keuangan Nomor 243/PMK.03/2014.Surat

Pemberitahuan $(S P T)$. Menteri Keuangan Republik Indonesia

Peraturan Pemerintah Nomor 28 tahun 2000.Usaha dan Peran Masyarakat Jasa Konstruksi.Presiden Republik Indonesia

Peraturan Pemerintah Nomor 140 tahun 2000.Pajak Penghasilan atas Pengahasilan dari Usaha Jasa Konstruksi.Presiden Republik Indonesia

Peraturan Pemerintah Nomor 40 Tahun 2009.Perubahan atas Peraturan Pemerintah Nomor 51 Tahun 2008.Presiden Republik Indonesia

Surat Edaran Direktorat Jenderal Pajak No.SE-13-PJ.42/2002.Pelaksanaan

Perlakuan Pajak Penghasilan atas Penghasilan dari Usaha Jasa Konstruksi.Direktorat Jenderal Pajak Republik Indonesia

Undang-Undang Ketentuan Umum dan Tata Cara Perpajakan Nomor 16 Tahun 2009.Penetapan Peraturan Pemerintah Pengganti Undang- 
Jurnal Akuntansi dan Bisnis, Vol. 4 (1) Bulan (Mei) 2018, p-ISSN:2243-3071 e-ISSN: 2503-0337

Undang Nomor 5 Tahun 2008.

Presiden Republik Indonesia

Undang-Undang Perpajakan Nomor 36 Tahun

2008.Perubahan Keempat atas

Undang-Undang Nomor 7 Tahun

1983.Presiden Republik Indonesia

www.pajak.go.id 